\title{
Total body irradiation is a crucial risk factor for developing secondary carcinomas after allogeneic hematopoietic stem cell transplantation in childhood
}

\author{
P. KESLOVA ${ }^{1, *}$, R. FORMANKOVA ${ }^{1}$, P. RIHA ${ }^{1}$, L. SRAMKOVA ${ }^{1}$, M. SNAJDEROVA ${ }^{2}$, B. MALINOVA ${ }^{3}$, A. LUKS ${ }^{1}$, J. STERBA ST. $^{4}$, STARY ${ }^{1}$, P. SEDLACEK ${ }^{1}$ \\ ${ }^{1}$ Department of Pediatric Hematology and Oncology, University Hospital Motol, $2^{\text {nd }}$ Medical School, Charles University Prague, Prague, Czech \\ Republic; ${ }^{2}$ Department of Pediatrics, University Hospital Motol, $2^{\text {nd }}$ Medical School, Charles University Prague, Prague, Czech Republic; \\ ${ }^{3}$ Department of Oncology, University Hospital Motol, $2^{\text {nd }}$ Medical School, Charles University Prague, Prague, Czech Republic; ${ }^{4}$ Department of \\ Pediatric Oncology, University Hospital Brno and School of Medicine, Masaryk University, Brno, Czech Republic
}

${ }^{*}$ Correspondence: petra.keslova@fnmotol.cz

Received February 14, 2020 / Accepted March 30, 2020

\begin{abstract}
Allogeneic hematopoietic stem cell transplantation (HSCT) has become a standard part of therapy for a variety of malignant and non-malignant disorders. With improved outcomes after HSCT, increasing attention has been drawn to late complications in long-term survivors. The development of secondary malignancies is recognized as one of the most serious complications. We have evaluated data from 426 patients ( 272 males, 154 females) who underwent allogeneic transplantation at a median age of 7.9 years from 1989 till 2017 and were alive more than one year after transplantation for the occurrence of secondary solid tumors. We have documented the occurrence of secondary solid tumors in 20 patients (4.7\%). The median duration of the development of secondary solid cancer from HSCT was 11.7 (range, 5.4-21.5 years). 18 out of 20 patients (90\%) had total body irradiation (TBI) $12-14.4$ Gy as a part of a conditioning regimen. All but two had transplantation for malignant disease. All patients underwent surgery and/or chemo-radiotherapy. Eighteen are alive, and two died due to the progression of their secondary malignancy. The most frequent solid cancer was thyroid carcinoma ( $\mathrm{n}=9$ ). Cumulative incidence of secondary solid cancer in all groups was $15.2 \pm 3.9 \%$, in a group using TBI based regimen $34.7 \pm 8.9 \%$, in non-TBI (only chemo) group was $1.5 \pm 1.1 \%$. Overall, the cumulative incidence is statistically significantly different between the TBI based and non-TBI (chemo only) group. The incidence and number of complications following allogeneic HSCT in childhood are increasing in time. The early diagnosis of secondary malignancies is one of the key tasks of long-life multidisciplinary post-transplant care.
\end{abstract}

Key words: total body irradiation, secondary carcinoma, allogeneic hematopoietic stem cell transplantation, childhood, risk factor, chronic graft versus host disease

Allogeneic hematopoietic stem cell transplantation (HSCT) has become a standard part of therapy for a variety of malignant and non-malignant disorders. The number of HSCT survivors is growing [1], with a current estimate of one half million worldwide. Long term survivors are at high risk for many late effects including the development of subsequent solid cancer [2]. The incidence of second cancers is two-eight-fold higher than the rate expected in the general adult population and being in $2-6 \%$ at ten years and $6-13 \%$ at fifteen years after HSCT. The increased rate of second cancers may be a result of chemotherapy and radiation conditioning used for transplantation, immunosuppression, immune dysregulation after transplantation, the chemotherapy, and radiotherapy the patient received before transplantation [3]. Much of the long-term complication, including the develop- ment of second cancers has been carried out in a combination of adults and children or adult patient population only, and survival and outcome observed in these cohorts may not reflect the expected results among pediatric transplanted patients. Children may be mainly at increased risk secondary to their long-life expectancy and potentially increased sensitivity of proliferating tissue to carcinogens. Those who undergo allogeneic HSCT are at significantly increased risk of secondary cancers compared with pediatric cancer survivors treated without HSCT $[4,5]$. The risk of radiation-induced second cancers is well described in the pediatric Hodgkin disease population. Bhatia et al. [6] reported the cumulative incidence for second solid malignancy at $7.3 \%$ at 20 years, increasing to $23.5 \%$ at 30 years. Breast cancer was a common solid malignancy, followed by thyroid, bone, colorectal, and 
gastric cancers. Some studies of second malignancy occurrence after allogeneic HSCT describe a significant association with total body irradiation (TBI). Curtis et al. found a highly significant dose-related with high dose TBI [7]. Socie et al. reported a 3.1-fold risk with high dose TBI [8]. The risk of developing a non-squamous cell cancer is highly associated with younger age at HSCT and the use of radiation in the conditioning regimen. Radiation is also a significant factor for the other solid tumors, particularly cancers of the breast, thyroid, brain, central nervous system, bone and connective tissue, and melanoma. Chronic graft versus host disease (GVHD) and immunosuppressive therapy are associated with squamous cell cancers of the skin and mucosa [3]. Overall survival varied by secondary cancer type. Secondary cancer was the cause of death in most patients, who died following the development of melanoma, central nervous system, oral cavity, thyroid, lung, lower gastrointestinal tract, and bone cancers [9].

The primary objective of our study was to analyze and describe the incidence and characteristics of secondary solid cancers in patients who have undergone HSCT at our center (HSCT Unit, University Hospital Motol, Prague). A secondary objective was to analyze the cumulative incidence of second cancer in all group patients in correlation with TBI group patients.

\section{Patients and methods}

A retrospective review of clinical records was conducted for patients who had undergone allogeneic HSCT in childhood and were subsequently diagnosed with secondary solid tumors. Patients are followed longitudinally, with yearly follow-up, including clinical and laboratory assessments. Other secondary malignancies, such as post-transplant lymphoproliferative disease or treatment-related myelodysplastic syndrome and secondary leukemia were excluded. Cases were collected from only one single center - HSCT Unit, Department of Pediatric Hematology and Oncology, University Hospital Motol, Prague. Clinical data included primary diagnosis, conditioning regimen, donor characteristics, GVHD history, and details of secondary cancer including the type of cancer, time of occurrence, tumor site and treatment (surgery, chemotherapy and/or radiation), and outcome of patients. Statistical analysis was carried out using the SPSS Statistical Package.

\section{Results}

From November 1989 to December 2017, 572 patients underwent allogeneic HSCT at HSCT Unit, Department of Pediatric Hematology and Oncology, University Hospital Motol, Prague. 426 patients (272 males, 154 females) who survived more than one year after transplant were enrolled in the study cohort. Eight patients with Fanconi anemia were excluded because of their susceptibility to cancer. The median age of the study cohort at transplant was 7.9 years (range 0.1-20.5). The median follow-up period after transplant was 9.9 (range 1.0-29.8 years). Patient characteristics and the conditioning regimens used are shown in Table 1. $287(67.3 \%)$ patients were transplanted due to malignant disease, mostly due to acute leukemia. 139 patients underwent HSCT for non-malignant disease, including severe immunodeficiency, aplastic anemia, and some metabolic

Table 1. Patient characteristics.

\begin{tabular}{|c|c|c|c|}
\hline \multirow[b]{2}{*}{ Patients } & & \multirow{2}{*}{$\begin{array}{c}n=\text { total } \\
426\end{array}$} & \multirow[t]{2}{*}{$\mathrm{n}=$ total $(\%)$} \\
\hline & & & \\
\hline \multirow[t]{2}{*}{ Gender } & Male & 272 & $63.9 \%$ \\
\hline & Female & 154 & $36,1 \%$ \\
\hline \multirow[t]{3}{*}{ Age at $1^{\text {st }}$ alloHSCT } & $0-6$ years & 166 & $39.1 \%$ \\
\hline & $7-15$ years & 201 & $47.1 \%$ \\
\hline & 16 years and above & 59 & $13.8 \%$ \\
\hline \multirow{6}{*}{$\begin{array}{l}\text { Diagnosis } \\
\text { Malignancies } \\
n=287(67.4 \%)\end{array}$} & ALL & 125 & $29.3 \%$ \\
\hline & AML & 56 & $13.1 \%$ \\
\hline & MDS & 61 & $14.3 \%$ \\
\hline & $\mathrm{CML}$ & 29 & $6.8 \%$ \\
\hline & other & 16 & $3.8 \%$ \\
\hline & Immunodeficiency & 62 & $14.6 \%$ \\
\hline \multirow{4}{*}{$\begin{array}{l}\text { Non-malignancies } \\
n=139(32.6 \%)\end{array}$} & Metabolic disease & 17 & $4 \%$ \\
\hline & $\mathrm{SAA}(+\mathrm{DBA})$ & $50+3$ & $12.5 \%$ \\
\hline & Osteopetrosis & 4 & $1.0 \%$ \\
\hline & other & 3 & $0.7 \%$ \\
\hline \multirow{4}{*}{$\begin{array}{l}\text { Donor } \\
\mathrm{n}=444\end{array}$} & MRD & 143 & $32.2 \%$ \\
\hline & MUD (9-10/10) & 256 & $57.7 \%$ \\
\hline & MM related donor & 8 & $1.8 \%$ \\
\hline & MM unrelated donor & 37 & $8.3 \%$ \\
\hline \multirow{3}{*}{$\begin{array}{l}\text { Stem Cell Source } \\
\mathrm{n}=456\end{array}$} & $\mathrm{BM}$ & 259 & $56.8 \%$ \\
\hline & PBSC & 166 & $36.4 \%$ \\
\hline & Cord blood & 31 & $6.8 \%$ \\
\hline \multirow{4}{*}{$\begin{array}{l}\text { Conditioning } \\
\text { TBI } n=146(34.3 \%)\end{array}$} & total & 146 & $32.1 \%$ \\
\hline & 2-10 Gy & 8 & $5.5 \%$ \\
\hline & $12 \mathrm{~Gy}$ & 112 & $76.1 \%$ \\
\hline & $14.4 \mathrm{~Gy}$ & 26 & $17.8 \%$ \\
\hline \multirow{4}{*}{$\begin{array}{l}\text { Conditioning } \\
\text { Non-TBI } n=280(65.7 \%)\end{array}$} & Busulfan (MAC) & 175 & $62.5 \%$ \\
\hline & Treosulfan & 34 & $12.1 \%$ \\
\hline & Cy only & 28 & $10 \%$ \\
\hline & other & 43 & $15.3 \%$ \\
\hline \multirow[t]{3}{*}{ aGVHD } & no & 176 & $41.3 \%$ \\
\hline & I-II & 231 & $54.2 \%$ \\
\hline & II-IV & 19 & $4.5 \%$ \\
\hline \multirow[t]{3}{*}{ cGVHD } & no & 308 & $72.3 \%$ \\
\hline & limited & 78 & $18.3 \%$ \\
\hline & extended & 40 & $9.4 \%$ \\
\hline
\end{tabular}

Abbreviations: ALL - acute lymphoblastic leukemia; alloHSCT - allogeneic hematopoietic stem cell transplantation; AML - acute myeloid leukemia; $\mathrm{BM}$ - bone marrow; BMFS - bone marrow failure syndrome; $\mathrm{CML}$ chronic myeloid leukemia; MAC - myeloablative conditioning; MDS myelodysplastic syndrome; MM - mismatched; MRD - matched related donor; MUD - matched unrelated donor; PBSC - peripheral blood stem cells; SAA - severe aplastic anemia; TBI - total body irradiation 
disorders. One hundred and forty-six patients (34.3\%) had total body irradiation (TBI), mostly 12.0-14.4 Gy as a part of the conditioning regimen.

Twenty patients (4.7\%) developed secondary solid tumors in median 11.7 (range, 5.4-21.5 years) after HSCT. The median patient's age at diagnosis of solid cancer was 23.4 (range, 11.8-35.1 years). Eleven patients (55\%) were males, and nine (45\%) were females. The most frequent cancer was thyroid carcinoma $(n=9)$, followed by oral cavity cancers $(n=3)$, melanomas $(n=3)$, malignant schwannomas $(n=2)$, peritoneal mesothelioma $(n=1)$, basal cell carcinoma $(n=1)$, breast cancer $(\mathrm{n}=1)$. The duration from HSCT to solid cancer diagnosis according to the cancer type is shown in Table 2. All but two patients underwent HSCT for malignant disease. The most frequent primary diagnosis was acute lymphoblastic leukemia $(n=13)$, chronic myeloid leukemia $(n=3)$, myelodysplastic syndrome $(n=2)$. Two patients were transplanted due to severe aplastic anemia (SAA). TBI based conditioning using 12-14.4 Gy was the most common preparative regimen, documented in 18 out of 20 patients (90\%). Cumulative incidence of secondary solid cancer in all groups (426 patients/20 tumors) was $15.2 \pm 3.9 \%$ (Figure 1). In a group using TBI based regimen (146 patients/18 tumors) was $34.7 \pm 8.9 \%$ (Figure 2 ), in non-TBI (only chemo) group (280 patients/2 tumors) was $1.5 \pm 1.1 \%$. Overall, the cumulative incidence is statistically significantly different between the TBI based and non-TBI (chemo only) group (Log Rank
$<0.001$; Figure 3). All patients were managed with surgery $(100 \%)$ with $(40 \%)$ or without $(60 \%)$ adjuvant radiation and/or chemoradiation therapy. With a duration follow-up of 5.2 years, 17 patients $(85 \%)$ are second cancer-free, one patient alive with breast cancer in palliative treatment. Two females died due to other carcinomas (invasive carcinoma of the tongue, malignant schwannoma) 2.5 and 3.0 years after diagnosis. Characteristics and management of second cancers are shown in Table 2, TBI and cGVHD history in Table 3.

\section{Discussion}

The risk of malignancy following stem cell transplantation, especially after irradiation in conditioning seems to depend not only on the dose of radiation administered but also on the type of first cancer, the type of chemotherapy used, the age, the presence of chronic graft versus host disease (cGVHD) and duration of follow-up [5, 10, 11]. Only a few studies have investigated survivors who received total body irradiation for HSCT, especially in childhood. Most of these studies describe especially the risk of thyroid cancers [11-14]. Three retrospective studies reported the results of ultrasound examination for the detection of thyroid nodules and/or carcinoma during the follow-up of patients receiving TBI as a part of the conditioning regimens during childhood. One of these studies, on 42 patients surviving for at least ten

Table 2. Characteristics and management of patients with secondary solid cancer.

\begin{tabular}{|c|c|c|c|c|c|c|c|c|c|c|}
\hline G & dg & Type of tumor & $\begin{array}{l}\text { Age at } \\
\text { HSCT }\end{array}$ & $\begin{array}{l}\text { HSCT } \\
\text { donor }\end{array}$ & $\begin{array}{c}\text { HSCT } \\
\text { conditioning }\end{array}$ & $\begin{array}{c}\text { Age at } \\
\text { tumor dg }\end{array}$ & $\begin{array}{c}\text { HSCT-Tu } \\
\text { (years) }\end{array}$ & Site of tumor & treatment & outcome \\
\hline $\mathrm{F}$ & ALL & Oral Ca & 16.6 & MSD & TBI12+Cy & 31.9 & 15.3 & tongue & surgery & Alive \\
\hline $\mathrm{F}$ & SAA & Thyroid Ca & 3.2 & MFD & TBI14.4+Cy & 18.5 & 15.3 & thyroid gl. & surgery & Alive \\
\hline $\mathrm{F}$ & ALL & Oral Ca & 14.8 & MSD & TBI12+Mel & 32.6 & 17.8 & tongue & RT, CH & Died \\
\hline M & ALL & Melanoma & 17.0 & MUD & TBI12+Cy & 29.8 & 12.7 & skin & surgery & Alive \\
\hline $\mathrm{F}$ & ALL & Thyroid Ca & 6.5 & MUD & TBI12+Cy & 23.6 & 17.1 & thyroid gl. & surgery & Alive \\
\hline M & ALL & Oral Ca & 6.9 & MSD & $\mathrm{TBI} 12+\mathrm{VP}$ & 17.8 & 10.9 & tongue & surgery, RT & Alive \\
\hline $\mathrm{F}$ & CML & Thyroid Ca & 12.4 & MUD & TBI14.4+Cy & 27.9 & 15.5 & thyroid gl. & surgery & Alive \\
\hline M & SAA & Schwannoma & 11.9 & MUD & TBI14.4+Cy & 23.2 & 11.3 & neck & surgery, RT & Alive \\
\hline M & ALL & Mesothelioma & 15.5 & MSD & TBI12+VP & 26.0 & 10.5 & peritoneum & surgery, $\mathrm{CH}$ & Alive \\
\hline $\mathrm{F}$ & ALL & Schwannoma & 5.3 & MSD & TBI12+VP & 16.8 & 11.5 & mediastinum & surgery, $\mathrm{CH}, \mathrm{RT}$ & Died \\
\hline M & ALL & Thyroid Ca & 3.6 & MSD & TBI12+VP & 15.4 & 11.8 & thyroid gl. & surgery & Alive \\
\hline $\mathrm{F}$ & CML & Thyroid Ca & 8.7 & MUD & TBI14.4+Cy & 16.3 & 7.6 & thyroid gl. & surgery & Alive \\
\hline $\mathrm{M}$ & ALL & Thyroid Ca & 6.7 & MUD & TBI12+VP & 16.5 & 9.8 & thyroid gl. & surgery & Alive \\
\hline M & ALL & Thyroid Ca & 6.4 & MFD & TBI12+VP & 11.8 & 5.4 & thyroid gl. & surgery, IA & Alive \\
\hline M & ALL & Breast Ca & 15.4 & MUD & TBI12+VP & 25.1 & 9.7 & breast & surgery, $\mathrm{CH}$ & Alive \\
\hline $\mathrm{F}$ & MDS & Thyroid Ca & 9.5 & MUD & BuCyMel & 17.7 & 8.2 & thyroid gl. & surgery, IA & Alive \\
\hline $\mathrm{F}$ & CML & Basal cell Ca & 17.4 & MUD & TBI14.4+Cy & 35.1 & 17.7 & skin & surgery & Alive \\
\hline M & MDS & Melanoma & 13.1 & MUD & BuCyMel & 24.4 & 11.3 & skin & surgery & Alive \\
\hline M & ALL & Thyroid Ca & 6.2 & MUD & TBI12+VP & 27.7 & 21.5 & thyroid gl. & surgery, IA & Alive \\
\hline M & ALL & Melanoma & 5.8 & MSD & TBI12+VP & 18.5 & 12.7 & skin & surgery & Alive \\
\hline
\end{tabular}

Abbreviations: M - male; F - female; G - gender; ALL - acute lymphoblastic leukemia; CML - chronic myeloid leukemia; MDS - myelodysplastic syndrome; MFD - matched family donor; MSD - matched sibling donor; MUD - matched unrelated donor; TBI - total body irradiation; Bu - busulphan; Cy - cyclophosphamide; Mel - melphalan; VP - etoposide; RT - radiotherapy; CH - chemotherapy; IA - iodine ablation 


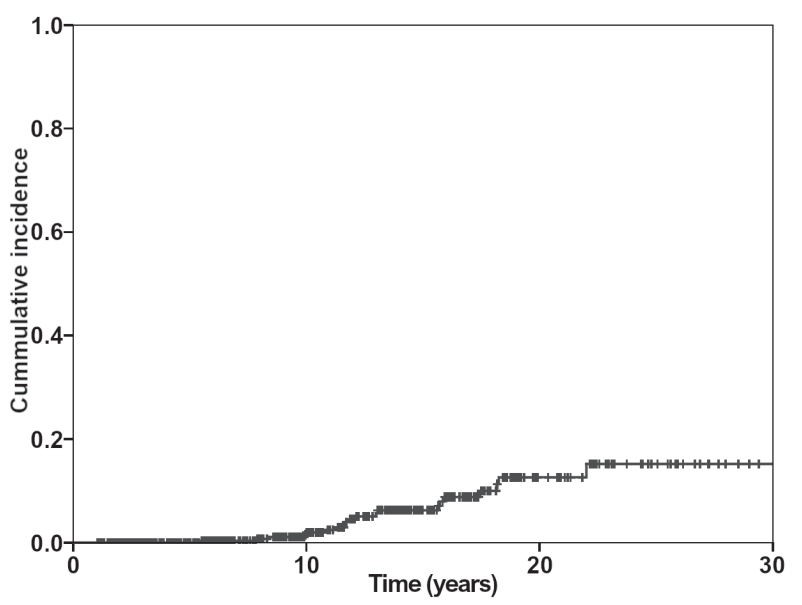

Figure 1. The cumulative incidence of secondary cancer. All patients $n=426$, second tumor $n=20$, cumulative incidence $15.2 \pm 3.9 \%$

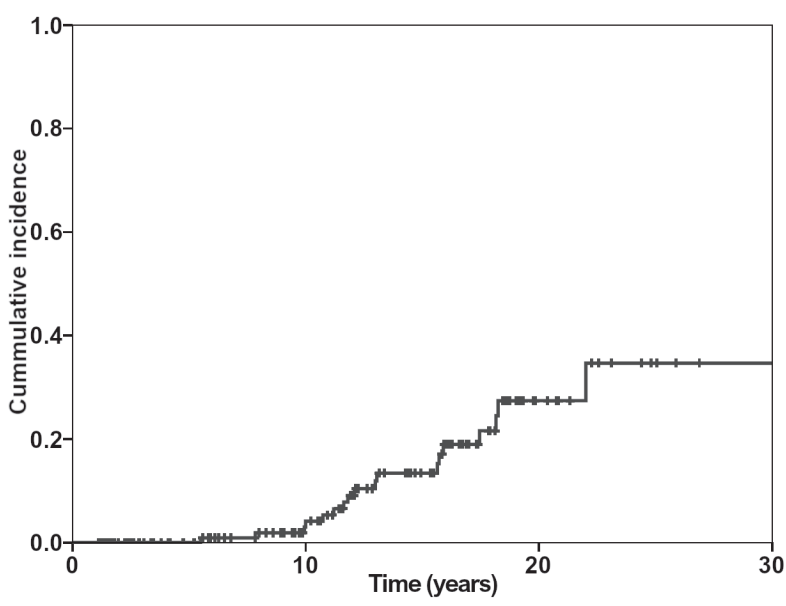

Figure 2. The cumulative incidence of secondary cancer in TBI patients only. TBI patients only $-n=146$, second tumor $n=18$, cumulative incidence $34.7 \pm 8.9 \%$

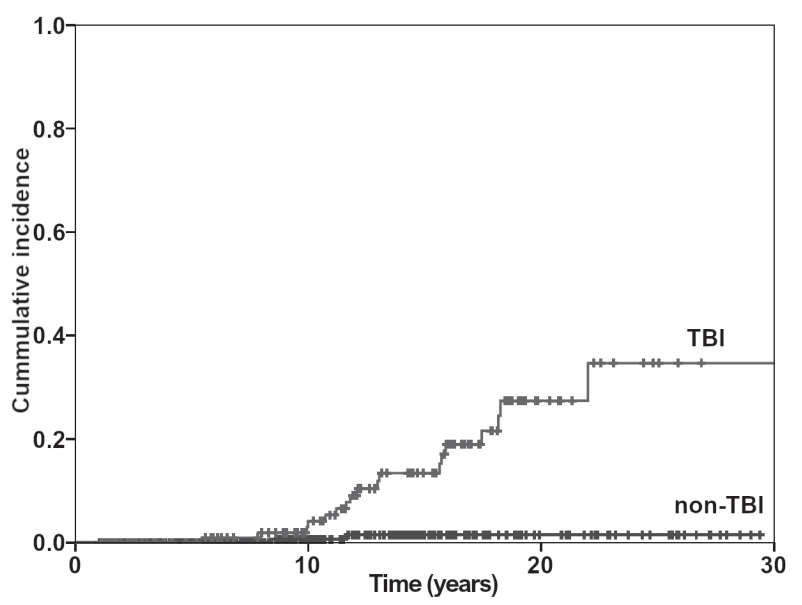

Figure 3. The cumulative incidence of secondary cancer - comparison TBI vs non TBI group. Comparison TBI vs. non-TBI group $(n=426)$ : TBI $n=146 / 18$ patients and chemo (non-TBI) $n=280 / 2$ patients, cumulative incidence TBI $34.7 \pm 8.9 \%$ and chemo $1.5 \pm 1.1 \%$ sign. $\log$ Rank: $\mathrm{p}<0.001$ years after TBI (median follow-up of 12 years), shows the incidence of thyroid carcinoma in $25 \%$ of 24 patients with nodules. This result is consistent with another study in which thyroid carcinomas have occurred in $29 \%$ of patients with detectable nodules $[11,15,16]$. Most of the cancers observed were papillary carcinoma and its follicular variants, with no observed systemic metastasis. The probability of developing metastatic disease is small. In our cohort, thyroid carcinoma was the most frequent subsequent solid tumor. We documented thyroid cancer in $9 / 20$ patients ( $45 \%$ of all) in a median of 11.8 years (range 5.4-21.5) years after HSCT. All but one underwent TBI as a part of the conditioning regimen. Histology confirmed the diagnosis of papillary cell carcinoma in all patients, therefore, surgery and subsequent substitution treatment with L-thyroxine were used in all of them. Three patients also received radioactive iodine ablation therapy. All were alive at the time of study 0.7 to 10.3 (median 5.1) years after surgical treatment. Cohen et al. in a large cohort (70,859 patients including adults and children) noted that the risk of developing secondary thyroid cancers after HSCT is higher in younger age groups $(<10$ years, RR, 24.61) and the time between HSCT and the diagnosis of secondary thyroid cancer is shorter compared with other solid tumors, particularly in children [12]. Pole et al. documented in their cohort (796 patients after HSCT), that secondary thyroid carcinoma developed at a median of 13.5 years (range 4.9-22.7), for other solid cancers, the time to develop was 13.8 years (range $1.3-17.3$ years) [4]. In our cohort, patients with secondary thyroid carcinoma were also younger at the time of transplant. The age at HSCT was 3.5 to 12.4 years (median 6.5) in comparison with other solid tumors group, where the age at HSCT was 5.3 to 17.4 (median 14.8) years. Secondary thyroid cancers occurred at a median of 11.8 years (range 5.4-21.5), similar for other solid cancers the time to diagnosis was 11.4 years (range 9.7-17.8). Only a part of patients found to have carcinoma had some clinical symptoms or abnormal thyroid gland function, most of them were asymptomatic. In our cohort, 4/9 (44\%) patients had abnormal thyroid gland tests. Physical examination is not a reliable method for detecting thyroid nodules, and ultrasound scans are generally required for thyroid nodules screening followed by FNAB (fine-

Table 3. Patients with secondary solid cancer - GVHD and TBI history.

\begin{tabular}{lccc}
\hline Total of 20 patients & Yes/No & N & $\%$ \\
\hline TBI based conditioning & Yes & 18 & $90 \%$ \\
& No & 2 & $10 \%$ \\
cGVHD after HSCT & Yes & 10 & $50 \%$ \\
& No & 10 & $50 \%$ \\
cGVHD at time of secondary cancer diagnosis & Yes & 4 & $20 \%$ \\
& No & 16 & $80 \%$ \\
\hline
\end{tabular}

Abbreviations: GVHD - graft versus host disease; cGVHD - chronic graft versus host disease; - total body irradiation 
needle aspiration biopsy) for the management of suspected lesions. FNAB was performed in case if an ultrasound scan revealed thyroid nodules $>5-8 \mathrm{~mm}$ in diameter, depending on the ultrasound characteristics of these nodules [11]. With the increasing use of ultrasound scans and FNAB, thyroid carcinoma tends to be diagnosed very accurately at the early stages [17]. An annual routine thyroid ultrasound examination, a non-invasive and relatively inexpensive procedure should be carried out on all HSCT survivors, especially those who were transplanted at an early age and following TBI-based conditioning [11, 12, 15]. Irradiation has shown to increase the risk for non-squamous cell carcinomas, while chronic GVHD appears to increase the risk of squamous cell carcinomas [18]. CNS, bone, and soft tissue cancers have shown to be significantly associated with radiation exposure too $[9,18]$. Analysis of a large and highly characterized series of patients with oral epithelial dysplasia (OED) and oral squamous cell carcinoma (OSCC) showed that oral cGVHD might be considered a potential risk factor for oral cancer. The tongue was the most common site (56\%) and the most frequent clinical features at diagnosis were plaques (50\%), exophytic masses (39\%), and ulcers (28\%). Carefully coordinated long-term follow-up by a comprehensive cancer team that includes oral medicine expertise is recommended, and patients should be well-informed of cancer risk. The frequent oral evaluations may have contributed to an earlier diagnosis of oral cancer [10]. In our cohort, three patients developed OSCC; all after TBI based conditioning, all with oral GVHD. In all of them, the primary site was tongue; clinical features at diagnosis were plagues (1 patient) and ulcers ( 2 patients). Two of them were managed with surgery; one also received radiotherapy and had neck dissection as a part of the surgical management. One remaining patient with involvement of the back of the tongue was treated with repeating chemoradiation and died after relapse. Patients with Fanconi anemia (FA) were excluded from our cohort due to higher susceptibility to cancer. There is increasing risk and an earlier median age for cancer in FA transplanted patients $[19,20]$. In our center, only one out of eight FA patients developed malignancy. He was transplanted in 5.2 years of age using the FluCy conditioning regimen and was diagnosed with colorectal carcinoma 10.2 years after HSCT. He underwent total colectomy and proctectomy and remained in remission 1.8 years after diagnosis.

In summary, allogeneic hematopoietic stem cell transplantation is a potentially curative therapy for a variety of malignant and non-malignant disorders. With the improved outcome, increasing attention has been drawn to late complications in long-term survivors. Secondary malignancies are rare but devastating complications. Pediatric patients who undergo allogeneic transplantation are at significantly increased risk of developing a secondary malignancy. Many of these cancers occurred at a younger age than primary cancers in the general population. The findings of our study present a single-center experience with the develop- ment and outcome of subsequent cancers. Patients with TBI based regimen had high and in time, increasing incidence of secondary cancers. TBI remains an important part of the conditioning regimen, especially in patients with ALL. Data of prospective international study show that pediatric patients with ALL older than 4 years transplanted from MSD or MUD have benefit more from TBI/etoposide compared to chemotherapy conditioning only (unpublished, personal communication). Lifelong screening is recommended for all transplant survivors according to established center guidelines, including guidelines for secondary cancer screening and prevention. Primary care and especially transplant physicians must be aware of the risk of subsequent malignancy following HSCT.

Acknowledgments: The authors wish to thank all of the patients, families, and referring physicians who contributed invaluable clinical information. This work was partly supported by the Ministry of Health, Czech Republic for conceptual development 00064203 University Hospital Motol.

\section{References}

[1] GRATWOHL A, PASQUINI MC, ALJURF M, ATSUTA Y, BALDOMERO $\mathrm{H}$ et al. Worldwide Network for Blood and Marrow Transplantation (WBMT). One million haemopoietic stem-cell transplants: a retrospective observational study. Lancet Haematol 2015; 2: e91-100. https://doi.org/10.1016/ S2352-3026(15)00028-9

[2] INAMOTO Y, MATSUDA T, TABUCHI K, KUROSAWA S, NAKASONE $\mathrm{H}$ et al. Outcomes of patients who developed subsequent solid cancer after hematopoietic transplantation. Blood Adv 2018; 2: 1901-1913. https://doi.org/10.1182/ bloodadvances.2018020966

[3] BIPIN N, GRIFFITH ML, JAGASIA S, LEE J. How I treat late effects in adults after allogeneic stem cell transplantation. Blood 2011; 117: 3002-3009. https://doi.org/10.1182/ blood-2010-10-263095

[4] POLE JD, DARMAWIKARTA D, GASSAS A, ALI M, EGLER $M$ et al. Subsequent malignant neoplasms in pediatric cancer patients treated with and without hematopoietic SCT. Bone Marrow Transplant 2015; 50: 721-726. https://doi. org/10.1038/bmt.2015.4

[5] LOWE T, BHATIA S, SOMLO G. Second malignancies after allogeneic hematopoietic cell transplantation. Biol Blood Marrow Transplant 2007; 13: 1121-1134. https://doi. org/10.1016/j.bbmt.2007.07.002

[6] BHATIA S, ROBISON LL, OBERLIN O, GREENBERG M, BUNIN G et al. Breast cancer and other second neoplasm after childhood Hodgkin's disease. N Engl J Med 1996; 334: 745-751. https://doi.org/10.1056/NEJM199603213341201

[7] CURTIS RE, ROWLINGS PA, DEEG HJ, SHRINER DA, SOCÍE $G$ et al. Solid cancers after bone marrow transplantation. N Engl J Med 1997; 336: 897-904. https://doi. org/10.1056/NEJM199703273361301 
[8] SOCIE G, CURTIS RE, DEEG HJ, SOBOCINSKI KA, FILIPOVICH AH et al. New malignant diseases after allogeneic marrow transplantation for childhood acute leukemia. J Clin Oncol 2000; 18: 348-357. https://doi.org/10.1200/ JCO.2000.18.2.348

[9] EHRHARDT MJ, BRAZAUSKAS R, HE W, RIZZO JD, SHAW BE. Survival of patients who develop solid tumors following hematopoietic stem cell transplantation. Bone Marrow Transplant 2016; 51: 83-88. https://doi.org/10.1038/ bmt.2015.203

[10] MAVARDI H, ELAD S, CORREA ME, STEVENSON K, WOO SB et al. Oral epithelial dysplasia and squamous cell carcinoma following allogeneic hematopoietic stem cell transplantation: clinical presentation and treatment outcomes. Bone Marrow Transplant 2011; 46: 884-891. https:// doi.org/10.1038/bmt.2011.77

[11] VIVANCO M, DALLE JH, ALBERTI C, LESCOEUR B, YAKOUBEN K et al. Malignant and benign thyroid nodules after total body irradiation preceding hematopoietic cell transplantation during childhood. Eur J Endocrinol 2012; 167: 225-233. https://doi.org/10.1530/EJE-12-0073

[12] COHEN A, ROVELLI A, MERLO F, VAN LINT MT, LANINO E et al. Risk for secondary thyroid carcinoma after hematopoietic stem-cell transplantation: An EBMT Late Effects Working Party study. J Clin Oncol 2007; 25: 2449-2454. https://doi.org/10.1200/JCO.2006.08.9276

[13] TAYLOR AJ, CROFT AP, PALACE AM, WINTER DL, REULEN RC et al. Risk of thyroid cancer in survivors of childhood cancer: Results from the British Childhood Cancer Survivor Study. Int J Cancer 2009; 125: 2400-2405. https:// doi.org/10.1002/ijc. 24581
[14] BHATTI P, VEIGA LH, RONCKERS CM, SIGURDSON AJ, STOVALL $M$ et al. Risk of second primary thyroid cancer after radiotherapy for a childhood cancer in a large cohort study: an update from the Childhood Cancer Survivors study. Radiat Res 2010; 174: 741-752. https://doi. org/10.1667/RR2240.1

[15] COHEN A, ROVELLI A, VAN LINT MT, MERLO F, GAIERO A et al. Secondary thyroid carcinoma after allogeneic bone marrow transplantation during childhood. Bone Marrow Transplant 2001;28: 1125-1128. https://doi.org/10.1038/ sj.bmt. 1703290

[16] FARACI M, BARRA S, COHEN A, LANINO E, CRISOLIA $F$ et al. Very late nonfatal consequences of fractionated TBI in children undergoing bone marrow transplant. Int J Radiat Oncol Biol Phys 2005; 63: 1568-1575. https://doi. org/10.1016/j.ijrobp.2005.04.031

[17] BRIGNARDELLO E, CORRIAS A, ISOLATO G, PALESTINI N, CORDERO DI MONTEZEMOLO L et al. Ultrasound screening for thyroid carcinoma in childhood cancer survivors: a case series. J Clin Endocrinol Metab 2008; 93: 4840-4843. https://doi.org/10.1210/jc.2008-1528

[18] RIZZO JD, CURTIS RE, SOCIE G, SOBOCINSKI KA, GILBERT E et al. Solid cancers after hematopoietic cell transplantation. Blood 2009; 113: 1175-1183. https://doi. org/10.1182/blood-2008-05-158782

[19] ROSENBERG PS, SOCIE G, ALTER BP, GLUCKMAN E. Risk of head and neck squamous cell cancer and death in patients with Fanconi anemia who did and did not receive transplants. Blood 2005; 105: 67-73. https://doi.org/10.1182/ blood-2004-04-1652

[20] ALTER BP, GIRI N, SAVAGE SA, ROSENBERG PS. Cancer in the National Cancer Institute inherited bone marrow failure syndrome cohort after fifteen years of follow - up. Haematologica 2018; 103: 30-39. https://doi.org/10.3324/ haematol.2017.178111 